\section{B A Institute of \\ yk Business Administration \\ 六下 \\ Karachi \\ Leadership and Ideas for Tomorrow}

Business Review

Volume 16 Issue 1 January-June 2021

8-16-2021

\title{
Investment behavior during COVID pandemic: An evidence from emerging Asian Markets
}

Sana Tauseef

Institute of Business Administration (IBA)

Follow this and additional works at: https://ir.iba.edu.pk/businessreview

Part of the Finance and Financial Management Commons, Operations and Supply Chain Management Commons, and the Portfolio and Security Analysis Commons

(c) (i)

This work is licensed under a Creative Commons Attribution 4.0 International License.

\section{Recommended Citation}

Tauseef, S. (2021). Investment behavior during COVID pandemic: An evidence from emerging Asian Markets. Business Review, 16(1), 76-100. Retrieved from https://doi.org/10.54784/1990-6587.1265

This article is brought to you by iRepository for open access under the Creative Commons Attribution 4.0 License and is available at https://ir.iba.edu.pk/businessreview/vol16/iss1/4. For more information, please contact irepository@iba.edu.pk. 


\title{
Investment behavior during the COVID pandemic: An evidence from emerging Asian markets
}

\author{
Sana Tauseef
}

\begin{abstract}
This study investigates the investor behavior in Asian emerging markets during the COVID pandemic period and assesses the asymmetric patterns and the influence of global and regional return dynamics on local investor behavior. It uses daily firm-level data from January 2001 to December 2020 for nine Asian emerging countries: China, India, Indonesia, Korea, Malaysia, Pakistan, Philippines, Taiwan and Thailand to estimate the impact of extreme price movements, market liquidity and US and Chinese market returns on local return dispersions using a non-linear specification. The findings indicate that rational price behavior prevailed in all markets over the COVID period. Though herding manifested itself occasionally during the low trading volume days in the pandemic period; overall, herd formation was not observed conditioned on domestic or non-domestic factors. Infact, our comparison of pre-COVID and COVID periods shows a significant shift in investment behavior away from herding and in favor of market efficiency for emerging markets of China, India and Korea. The findings on prevalence of rational price behavior are unique and reflective of improved informational environment in Asian emerging markets.
\end{abstract}

Keywords Rational price behavior · Herding · Return dispersions · Pandemic

\section{Introduction}

Market efficiency hypothesis assumes that investors form rational expectations and make informed decisions based on their own independent analysis. As an alternate, behavioral finance argues that investors operate with cognitive and emotional biases and their decisions are not always optimal. One such systematic bias reflected in investors' behavior is herding. Herding occurs when investors imitate each other resulting in a large group of investors making same trading decisions. Such behavior may result due to rational investing as well.

\footnotetext{
Sana Tauseef

Institute of Business Administration, Karachi-Pakistan

E-mail: sasghar@iba.edu.pk

(c)Tauseef, S. 2021
} 
For example, investors using the same source of information or using similar methodologies reach to same investment decisions (Hirshleifer et al 1994). The rational herd behavior (also referred to as spurious herding) is more common among institutional investors who have access to homogenous information, use same analytical approaches or have similar dispositions towards certain stocks characteristics and their trading speeds up the price adjustment (Gompers and Metrick 2001). On the contrary, irrational herding (also referred to as true herding) occurs when investors blindly copy the trading actions of other investors rather than relying on their independent analysis. Herding backed by irrational investor behavior is of particular concern in context of asset pricing theories since such behavior may aggravate volatility, slow down price adjustment, create further mispricing and hence destabilize financial markets. Despite clear theoretical distinction between spurious and true herding, most empirical studies gauge the clustering of investment decisions irrespective of the underlying reasons for such behavior.

Recently, emerging markets have been an attraction for foreign investors owing to their rapid economic growth (OECD 2019). These markets are characterized as having less sophisticated investors, low transparency levels and information asymmetry. As a result, it is argued that traders in these markets may base their investment actions on decisions of others who may be more informed by following market consensus (Gelos and Wei 2005). Consequently, herd behavior is expected to be relatively stronger for emerging markets than developed markets (Chang et al 2000). However, existing literature from emerging Asian markets is limited. Furthermore, these emerging markets are focused on enhancing public equity, financial liberalization and economic integration. Indeed, Asian emerging markets of China, India and Japan have been ranked among the top ten markets based on the number of public equity listings over the period 2009-2018 (OECD 2019). As a matter of fact, market dynamics in these markets are evolving rapidly over time rendering the findings based on old data invalid and requiring reinvestigation of the investor behavior from these markets in the most recent environment. In this paper, we contribute to the literature by assessing the investor behavior in nine Asian emerging markets: China, India, Indonesia, Korea, Malaysia, Pakistan, Philippines, Taiwan and Thailand over the period from 2001 to 2020. Available studies from these countries focus mainly on investment behavior in individual countries. For instance, Tan et al (2008), Chiang et al (2010) and Chong et al (2017) investigated investor behavior in China; Prosad et al (2012) and Chauhan et al (2020) checked for herding in Indian market; Brahmana et al (2012) and Dehghani and Sapian (2014) conducted studies on herding from Malaysia; Akbar et al (2019), Rajput and Bhutto (2019) and Jabeen and Rizavi (2019) reported evidence of herding from Pakistan and Chang et al (2012) investigated herding in Taiwan. Findings of these studies from individual markets are based on different data periods making them incomparable. We include all Asian emerging countries in our study to provide a comparative analysis of rationality or herding across emerging countries in Asian region.

More specifically, we investigate whether investment behavior in the Asian emerging countries varies in its significance prior to and during the COVID- 


\section{S. Tauseef}

19 outbreak. Literature show that herding becomes more apparent during the period of crisis. For example, Goodfellow et al (2009) provided evidence that investors deviate away from rational behavior towards herding during market downswings. In addition, Zhou and Lai (2009) observed that investors are more likely to herd while selling stocks and less likely while buying. On similar lines, Chiang et al (2010) provided supportive evidence of herd formation in US and Latin American markets during the crisis periods. The recent COVID period presents a case to test the earlier reported findings. Hence, our study stresses on the presence of irrational investor behavior and change in investor behavior over the recent COVID outbreak period. Furthermore, in line with existing literature, we also investigate if investor behavior exhibits asymmetric properties conditional upon extreme market performance and extreme trading volume.

Finally, we test for the impact of two equity markets, US and China, on local investment behavior over the COVID period. We consider the impact of the US market since it is the most dominant international market. Further, the Chinese market is included because of its dominant position in the region and its significant economic partnership with most Asian emerging countries. In an integrated global environment, the investment behavior in one market is expected to be influenced by global factors and hence, findings on influence of these non-domestic factors would provide a hint about the level of integration of these markets.

Our empirical tests indicate the presence of rational investor behavior in all markets over the COVID period. Upon conditioning to market liquidity, we observe herding on low trading volume days for China, India, Korea and Pakistan; however, herd formation was not observed on any other occasion based on domestic or non-domestic factors. Furthermore, our comparison of the investor behavior in COVID and pre-COVID periods shows a shift in price behavior away from herding and in favor of market efficiency for China, India and Korea. Our findings, thus, support prevalence of efficient market conditions in Asian emerging markets and are of particular relevance to foreign portfolio investors. Disappearing herd behavior and a shift towards rational behavior in these markets in recent period is indicative of improved informational efficiency and transparency in these markets making the market destabilizing incidents less likely. Given the impressive growth of Asian emerging markets in recent years (OECD 2019) and the evidence of diversification opportunities that emerging markets offer (Conover et al 2002), prevalence of rational pricing in these markets is a positive news and should provide confidence to the global portfolio investors to increase their portfolio allocations in these markets.

The remainder of the paper is structured as follows: In section 2, we provide review of empirical studies on herding, section 3 presents the description of data and the methodological details. In section 4 , we provide the discussion of empirical results and in section 5 , we provide concluding remarks. 


\section{Literature review}

Empirical investigation of investment behavior in financial markets focuses on the cross-sectional return dispersions. Christie and Huang (1995) argued that investors are more likely to follow the market consensus during times of unusual market movements which would result in smaller cross-sectional dispersions. Chang et al (2000) extended the previous models by arguing that presence of herding can be detected by employing non-linear relationship between returns and dispersions. According to their framework, if herding exists, return dispersions may decrease or increase at a decreasing rate with an increase in market return.

Since the seminal works, a number of studies have been conducted to examine the investors' behavior in international equity markets. The literature on investor behavior from developed stock markets presents mixed findings. Christie and Huang (1995) tests provided evidence against herding behavior and in favor of rational pricing for US equity market. Chiang et al (2010) reported evidence of herding in Asian markets and selected developed markets. However, their study did not find indication of herding for US and Latin American markets. Similarly, Mobarek et al (2014) did not find significant herd behavior in European markets.

The evidence of herding behavior is stronger in emerging markets than in mature markets because more speculators having relatively short investment horizons are present in emerging markets (Chang et al 2000). Demirer and Kutan (2006) examined investor behavior in the two Chinese equity markets: Shanghai and Shenzhen Stock Exchange. Taking into context daily stock return data from 1999 to 2002 for 375 Chinese stocks, they found negligible evidence on herding. Infact, the study reported equity return dispersions to be significantly higher during periods of large changes in the aggregate market index. Considering the differing characteristics of investors on two exchanges in China, Tan et al (2008) investigated investor behavior in dual-listed Chinese A-share and B-share stocks and found evidence of herding within both the Shanghai and Shenzhen markets. Moreover, they provided evidence of herding in both rising and falling market conditions for Chinese stock market and reported herding to be more pronounced during timings of rising markets, high trading volume, and high volatility.

Evidence of herding is also available from other Asian emerging markets. For example, Prosad et al (2012) examined the stocks that make up Nifty 50 equity index in India over the period from 2006 to 2011 and documented presence of herding during the bull phase over periods of market stress. In a recent study, Chauhan et al (2020) also found evidence of herding from the Indian market. Their study observed that herding exists more significantly in large-cap stocks than in small-cap stocks and reported it as a significant risk factor which is priced in the Indian market.

Agarwal et al (2011) documented no evidence of herding found in investors' behavior across brokerage firms in Indonesia; however, herd behavior prevailed for both domestic and foreign investors associated with particular brokerage firms. Further, Putra, Rizkianto and Chalid (2017) confirmed presence of herd- 


\section{S. Tauseef}

ing in Indonesia and proved herding to be stronger in Indonesia than in Singapore.

Brahmana et al (2012) tested the role of herd behavior in determining the day-of-the week anomaly in Bursa Malaysia over the period from 1990 until 2010. They found evidence of Monday herding over complete sample period as well as sub-periods. Further, herd behavior did not exist in market downswings and market upswings through the week. Hence, the study reported herd behavior to be the determinant of Investor's Monday irrationality in Malaysian stock market. Dehghani and Sapian (2014) examined investors' herding behavior in the IPO aftermarket from 2001 to 2011 in Bursa Malaysia and provided evidence that the investors in the technology sector tend to follow the market movement during down market conditions. Significant herding in the technology sector was related to small firm size in the sector, which makes them considered to be the risky ones by the investors.

Akbar et al (2019) observed herding for five out of eleven industries in Pakistan and reported that stock trading volume is a predictor of herding than stock returns. Using time series data for the period from 2000 to 2016, the study not only reported significant evidence of herding behavior in the Pakistan stock market over the entire sample period but also found it to be more pronounced under extreme market conditions, market volatility and financial crisis. Further, it was found that herding behavior before any concerning crisis increased, whereas it decreased at the time of crisis. Javaira and Hassan (2015) and Yousaf et al (2018)) also confirmed prevalence of herding in Pakistan's equity market during the crisis period.

Chang et al (2012) reported that herding prevails in Taiwan market. Further, the study concluded that significant gains can be made based on portfolio construction strategies based on individual investors' herding. Moreover, Huang and Wang (2017) investigated the impact of changes in the volatility index on the investment behavior of market participants in the Taiwan stock market. They validated that investors' reaction to bad news is faster than to good news when their fear increases. In addition, they revealed that herding behavior tends to exist on days with a large trading volume. Recently, Jirasakuldech and Emekter (2020) investigated herding behavior of investors in Thailand under different market conditions, crisis periods, and major market structural changes. The study found that herding behavior occurs during an extreme market movement of negative or positive returns, in the declining market environment, during timeline when there is greater trading volume, and during economic downturn as measured by negative GDP output gap.

The evidence on presence of herding from Asian emerging markets is substantial; however, previous studies are focused on individual markets. We consider all nine Asian emerging markets in our sample and investigate investor behavior over the recent COVID-19 pandemic. Also, we test for the impact of two equity markets, US and China, on local investment behavior to provide evidence on the spillover effects of herding from the two dominant equity markets. 


\section{Data and methodology}

We used daily stock price data for all stocks listed on following nine Asian emerging markets based on MSCI market classification: China, India, Indonesia, Korea, Malaysia, Pakistan, Philippines, Taiwan and Thailand. We obtained the data for the entire population over the period January 2001 till December 2020 from Thomson-Reuters Data Stream. Along the lines of Christie and Huang (1995) and Chang et al (2000), our methodology relies on the idea that if investors' actions are based on collective actions of market, security returns would not deviate far from the market returns, hence indicating presence of herd behavior. For each country, we calculated the cross-sectional absolute deviation (CSAD) as measure of return dispersions:

$$
C S A D_{t}=\frac{\sum_{i=1}^{n}\left|R_{i, t}-R_{m, t}\right|}{n}
$$

where $R_{i}$ is individual stocks return and $R_{m}$ is return on respective market's major equity index. For each market, we divide our sample period into two subperiods: COVID period starts from the day first COVID case was reported in the respective country and ends on December 31, 2020 and pre-COVID period starts from January 01, 2001 and ends one day before the first COVID case was reported in the respective country. We report the equity index, date of first reported COVID case and total COVID cases for sample countries in table A1 in the appendix. We checked for the presence of herding or rational price behavior in the two periods and possibility of change in investor behavior over the pandemic period, using the following non-linear specification:

$$
\begin{gathered}
C S A D_{t}^{C O V I D}=\alpha+\beta_{1}^{C O V I D}\left|R_{m, t}^{C O V I D}\right|+\beta_{2}^{C O V I D}\left(R_{m, t}^{C O V I D}\right)^{2}+\epsilon_{t} \\
C S A D_{t}^{\text {pre-COVID }}=\alpha+\beta_{1}^{\text {pre-COVID }}\left|R_{m, t}^{\text {pre }-C O V I D}\right|+\beta_{2}^{\text {pre }-C O V I D}\left(R_{m, t}^{\text {pre }-C O V I D}\right)^{2}+\epsilon_{t}
\end{gathered}
$$

Given the rational asset pricing expectations, dispersions would increase with an increase in absolute market returns, reflected in the positive significant values of $\beta_{1}^{C O V I D}$ and $\beta_{1}^{\text {pre-COVID }}$ in the above model. In presence of herding, dispersions might decrease or increase at a decreasing rate, reflected in the negative significant values of $\beta_{2}^{C O V I D}$ and $\beta_{1}^{\text {pre-COVID }}$ (Chang et al 2000) and a significant difference in the two values would indicate a change in investor behavior over the pandemic period.

We investigate the asymmetric patterns of herding behavior over the COVID and pre-COVID periods with respect to extreme price movement and liquidity. In literature, one, five and ten percent in the upper and lower tails of market return and market trading volume are used to define extreme price movement and liquidity respectively. Owing to the small number of observations in the COVID period for each market, we consider ten percent of the highest and lowest return and trading volume within each period as extreme conditions. The asymmetric behavior with respect to extreme price movement is estimated as 
follows:

$$
\begin{aligned}
& C S A D_{t}^{C O V I D}=\alpha+\beta_{1} D_{u p}^{C O V I D}\left|R_{m, t}\right|+\beta_{2} D_{\text {down }}^{C O V I D}\left|R_{m, t}\right|+\beta_{3} D_{u p}^{C O V I D}\left(R_{m, t}\right)^{2} \\
& +\beta_{4} D_{\text {down }}^{C O V I D}\left(R_{m, t}\right)^{2}+\epsilon_{t} \\
& C S A D_{t}^{\text {pre-COVID }}=\alpha+\beta_{1} D_{u p}^{\text {pre-COVID }}\left|R_{m, t}\right|+\beta_{2} D_{\text {down }}^{\text {pre-COVID }}\left|R_{m, t}\right| \\
& +\beta_{3} D_{u p}^{\text {pre-COVID }}\left(R_{m, t}\right)^{2}+\beta_{4} D_{\text {down }}^{\text {pre-COVID }}\left(R_{m, t}\right)^{2}+\epsilon_{t}
\end{aligned}
$$

where $D_{u p}$ and $D_{\text {down }}$ are dummy variables which equal 1 for days with extreme positive and negative market returns, respectively. Significant negative (positive) values for of $\beta_{3}$ and $\beta_{4}$ would indicate presence of herd (rational) behavior on days of extreme price movement and $\beta_{4}<\beta_{3}$ would indicate more pronounced herding on days with negative market returns. The asymmetric behavior with respect to market liquidity is estimated as follows:

$$
\begin{gathered}
C S A D_{t}^{C O V I D}=\alpha+\beta_{1}\left|R_{m, t}\right|+\beta_{2}\left(R_{m, t}\right)^{2}+\beta_{3} D_{\text {high }}^{C O V I D}\left(R_{m, t}\right)^{2} \\
+\beta_{4} D_{\text {low }}^{\text {COVID }}\left(R_{m, t}\right)^{2}+\epsilon_{t} \\
\begin{aligned}
C S A D_{t}^{\text {pre-COVID }}=\alpha & +\beta_{1}\left|R_{m, t}\right|+\beta_{2}\left(\left(R_{m, t}\right)^{2}+\beta_{3} D_{\text {high }}^{\text {pre-COVID }}\left(R_{m, t}\right)^{2}\right. \\
& +\beta_{4} D_{\text {low }}^{\text {pre }} \operatorname{COVID}\left(R_{m, t}\right)^{2}+\epsilon_{t}
\end{aligned}
\end{gathered}
$$

where $D_{\text {high }}$ and $D_{\text {low }}$ are dummy variables which equal 1 for days with high and low market liquidity, respectively. Significant negative (positive) values for of $\beta_{3}$ and $\beta_{4}$ would indicate presence of herd (rational) behavior on days of high and low liquidity and $\beta_{3}<\beta_{4}$ would indicate more pronounced herding on days with high trading volume.

Finally, we test for the effect of US market and Chinese market on local investment behavior in sample markets over the COVID period using the following model:

$$
\begin{gathered}
C S A D_{t}^{C O V I D}=\alpha+\beta_{1}^{C O V I D}\left|R_{m, t}^{C O V I D}\right|+\beta_{2}^{C O V I D}\left(R_{m, t}^{C O V I D}\right)^{2}+\beta_{3}^{C O V I D}\left(R_{U S, t}^{C O V I D}\right)^{2}+\epsilon_{t} \\
C S A D_{t}^{C O V I D}=\alpha+\beta_{1}^{C O V I D}\left|R_{m, t}^{C O V I D}\right|+\beta_{2}^{C O V I D}\left(R_{m, t}^{C O V I D}\right)^{2}+\beta_{3}^{C O V I D}\left(R_{C h, t}^{C O V I D}\right)^{2}+\epsilon_{t}
\end{gathered}
$$

In the above model, $R_{U S}$ is US market return proxied through S\&P 500 index and $R_{C h}$ is Chinese market return proxied through Shanghai Composite Index. Significantly negative values of $\beta_{2}$ would indicate presence of domestic herding whereas significantly negative values of $\beta_{4}$ would indicate notable influence of return dynamics of US and Chinese markets on local investment behavior of respective Asian market. Estimations of regression coefficients in all tests are done using Newey and West (2017) approach to adjust for heteroscedasticity and autocorrelation. 


\section{Empirical results}

\subsection{Descriptive statistics}

In table 1 , we provide summary statistics for mean daily returns $\left(R_{m}\right)$ and cross-sectional absolute deviations $(C S A D)$ for sample countries. Mean daily return of sample countries is higher in the COVID period with the exception of Pakistan and Philippines. Over the COVID period, mean daily returns range between the lowest of -0.02 percent for Philippines and highest of 0.10 percent for Korea. Volatility, as measured by standard deviation of returns, is also higher in the COVID period for most countries. India and Philippines had most extreme daily price movements with minimum daily returns of -13.94 percent and -17.49 and maximum daily returns of 8.40 percent and 6.88 percent, respectively.

Mean daily cross-sectional deviations reduced in COVID period for sample countries except China, Korea and Malaysia. Mean daily dispersions for our sample range from lowest of 1.69 percent for China and highest of 3.69 percent for India in the pandemic period. We also report test statistics for Augmented Dicky-Fuller (ADF) test on return and dispersion series. These tests indicate that return and dispersion series for all sample countries exhibit stationarity.

\subsection{Investor behavior over COVID and Pre-COVID periods}

We begin our investigation of investor behavior in nine Asian markets by estimating Equation 2. We present our estimated results in table 2. Our results show positive coefficients on $\left|R_{m}\right|$ across all countries for both COVID and preCOVID periods. Furthermore, these values are significant with the exception of Korea and Malaysia in COVID period. In line with theoretical expectations based on rational asset pricing, these results confirm that return dispersions widen with increase in market returns across all countries. The coefficient of $\left(R_{m}\right)^{2}$ tests if the dispersions increase at a decreasing rate which would be indicative of herd behavior. We observe significant negative coefficient of $\left(R_{m, t}\right)^{2}$ for China in pre-COVID period only, whereas in the COVID period, none of the countries show significant negative coefficient on $\left(R_{m}\right)^{2}$. Infact, the positive values on the coefficient are significant for China, India and Korea in the COVID period and for Malaysia, Philippines and Thailand in the pre-COVID period.

In table 2, we also report the test statistic on the difference of coefficients on $\left(R_{m}\right)^{2}$ between the COVID and pre-COVID period. We observe significant change in investor behavior between the two periods for China, India, Korea and Philippines. For Philippines, positive significant coefficient of $\left(R_{m}\right)^{2}$ in preCOVID period turned to negative for COVID period indicating a shift away from rational pricing and towards herd formation; however, as noted above, herd behavior for Philippines in COVID period is not significant. In contrast, for China, India and Korea, negative coefficient of $\left(R_{m}\right)^{2}$ in pre-COVID period turned to positive for COVID period indicating a shift in price behavior away from herding. The significant difference in coefficient of $\left(R_{m}\right)^{2}$ between two periods along with significant positive coefficient in COVID period provides 
https://ir.iba.edu.pk/businessreview/vol16/iss1/4

DOI: https://doi.org/10.54784/1990-6587.1265

\section{S. Tauseef}

evidence of shift towards and prevalence of rational investor behavior in these countries. 


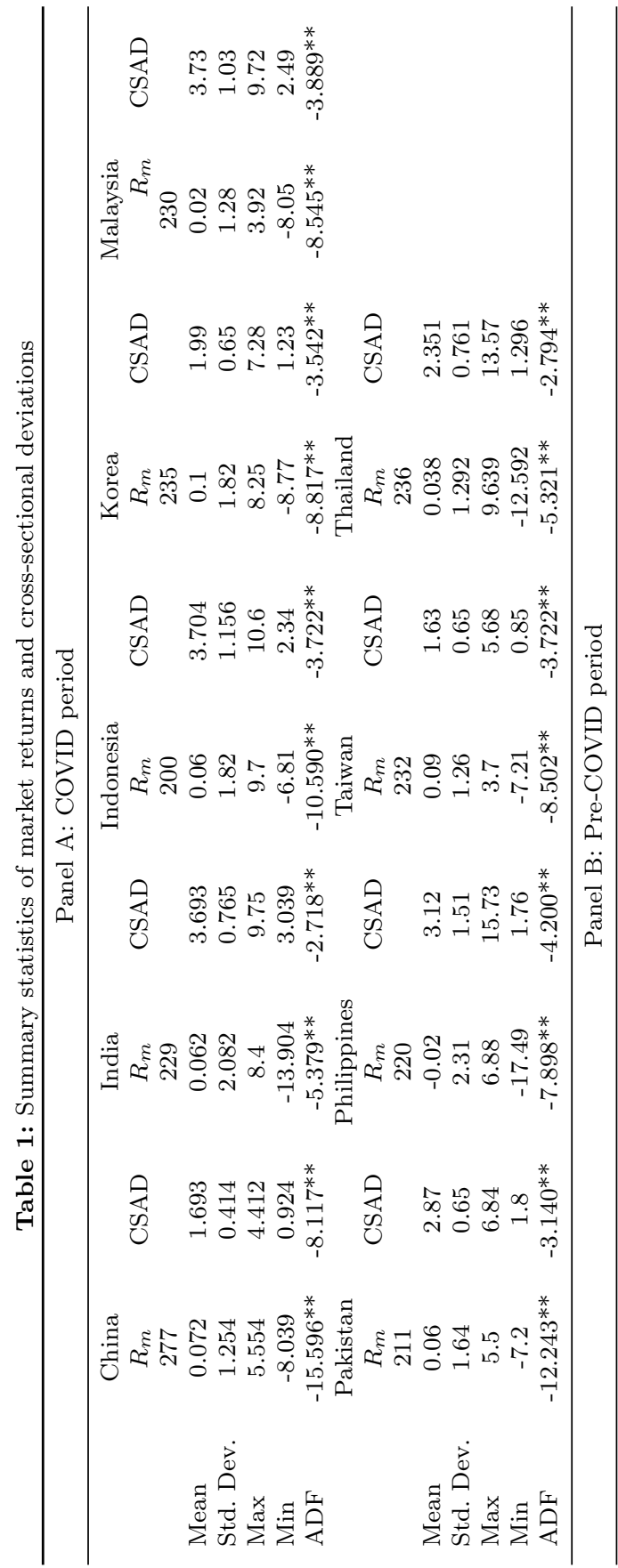

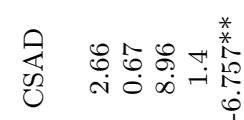

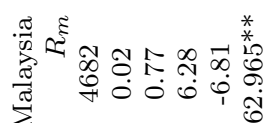

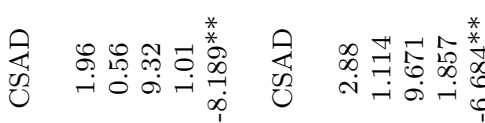

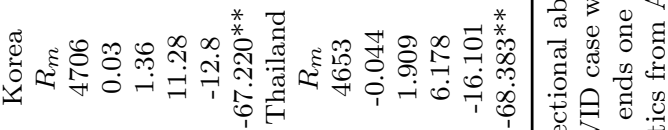

磪 西

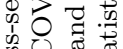

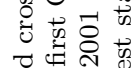

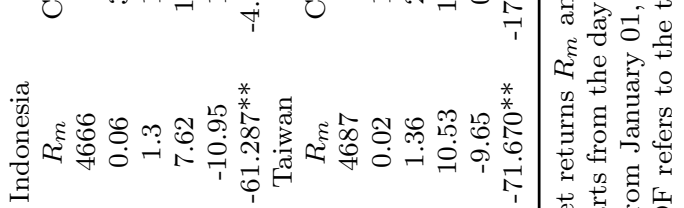

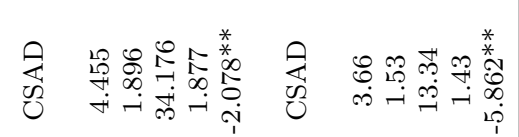

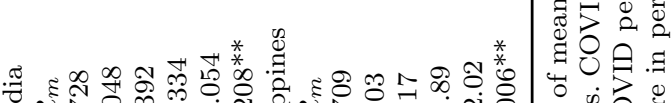

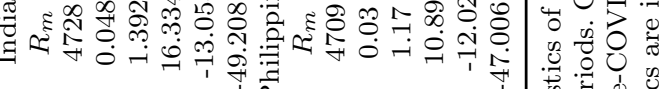
( 荷

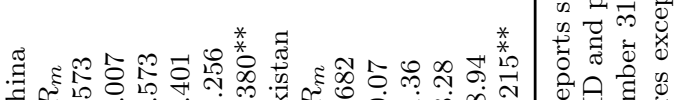

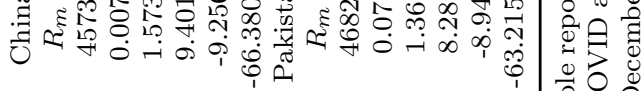

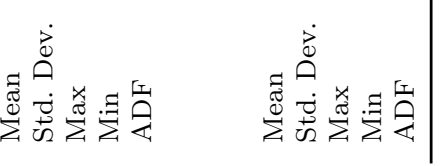
要考

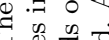

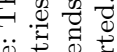




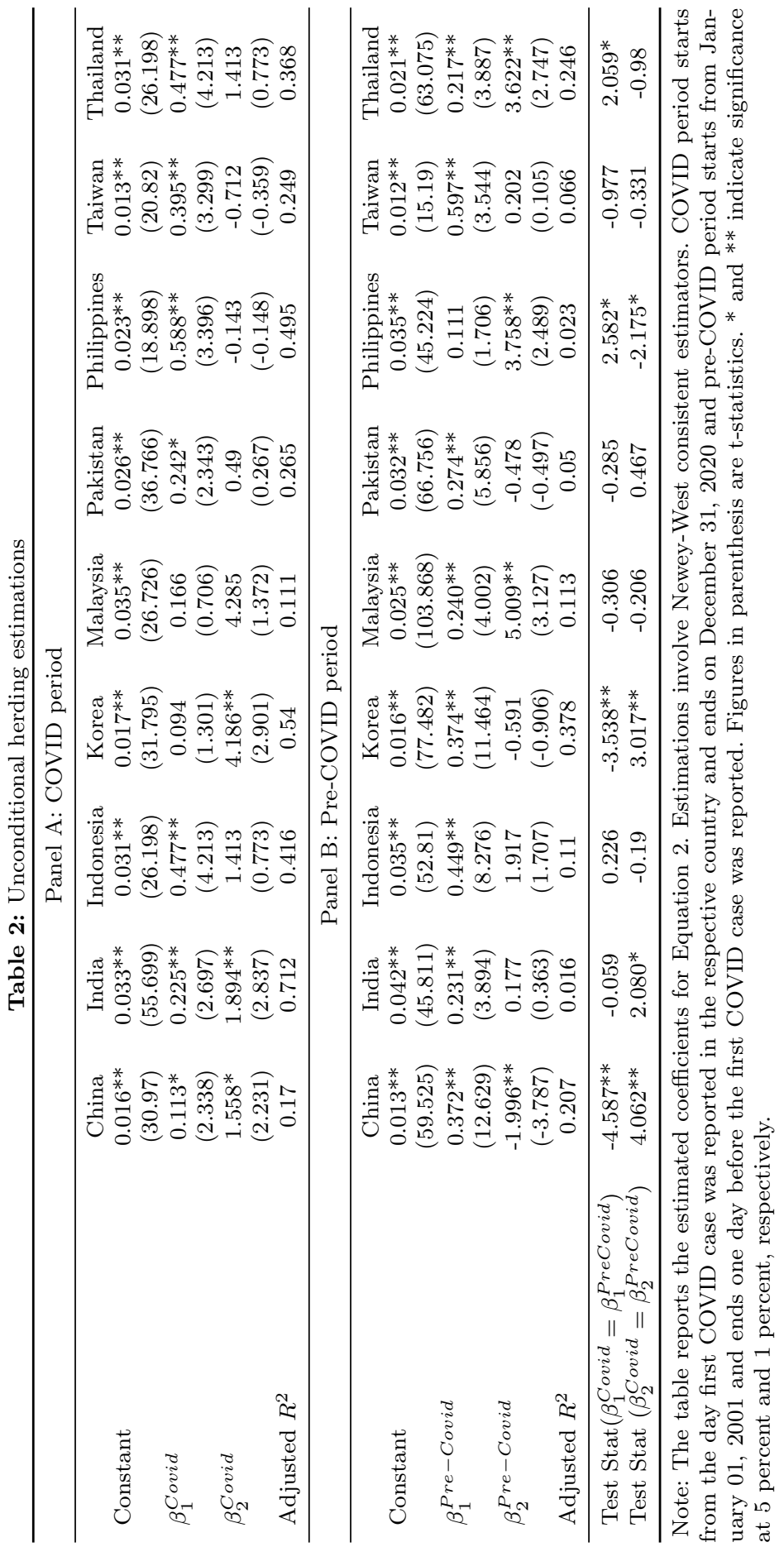




\subsection{Asymmetries in investor behavior}

We now test for the asymmetric patterns in investor behavior based on extreme price movements and market liquidity. Relationship between return deviations and market returns distinguishing between up and down markets is estimated using Equation 3 and results are reported in table 3. For the COVID period, coefficient on the linear term $\left|R_{m}\right|$ is significantly positive for Indonesia, Pakistan and Thailand in up market, and significantly positive for China, Pakistan, Philippines and Taiwan in down market. For the pre-COVID period, coefficients of $\left|R_{m}\right|$ are positive for all countries and significant for most countries. Coefficient on $\left(R_{m}\right)^{2}$ in both periods is either significantly positive or insignificantly negative for all countries except for China in pre-COVID period, providing an overall evidence against herding and in support of rational asset pricing.

We now turn our attention to the only market in our sample for which we capture evidence of herding in pre-COVID period. The coefficient of $\left(R_{m}\right)^{2}$ is significant negative for China in both up and down markets for pre-COVID period, suggesting a non-linear relationship between market return and dispersion. For example, based on the coefficients of $\left|R_{m}\right|(0.20)$ and $\left(R_{m}\right)^{2}(1.89)$ in up market, dispersion increases as market return increases till a maximum return of 5.32 percent. Maximum return is calculated by substituting the estimated coefficients of $\left|R_{m}\right|$ and $\left(R_{m, t}\right)^{2}$ into the quadratic relationship specified in Equation 3 . Beyond this threshold return, dispersion will decrease. The finding indicates presence of herding in Chinese market on days with extreme price movements. The difference between coefficients of $\left(R_{m}\right)^{2}$ for up and down markets is not significant indicating that market price movement is not a determinant of herding asymmetry in China. Furthermore, our results in table 3 again provide evidence that herd behavior disappeared and did not exist during the COVID period in China.

Investor behavior on days with high and low liquidity are estimated by Equation 4 and we present the results in table 4 . When conditioned on liquidity, we observe investors exhibiting herd behavior in some markets during both the periods. Specifically, herd formation is notable for China, India, Korea and Pakistan on low liquidity days in the COVID period. Similarly, for the pre-COVID period, we observe herd behavior in China, Malaysia and Taiwan on low liquidity days and in Korea on both low and high liquidity days. Furthermore, significant difference in the coefficients for high and low liquidity for some countries in either or both periods indicates asymmetric pattern in herd behavior based on market liquidity. However, our evidence of herd formation on days with low liquidity is in contrast with the findings of previous studies (Tan et al 2008; Indārs et al 2019) that reported herd formation in periods of high liquidity. 


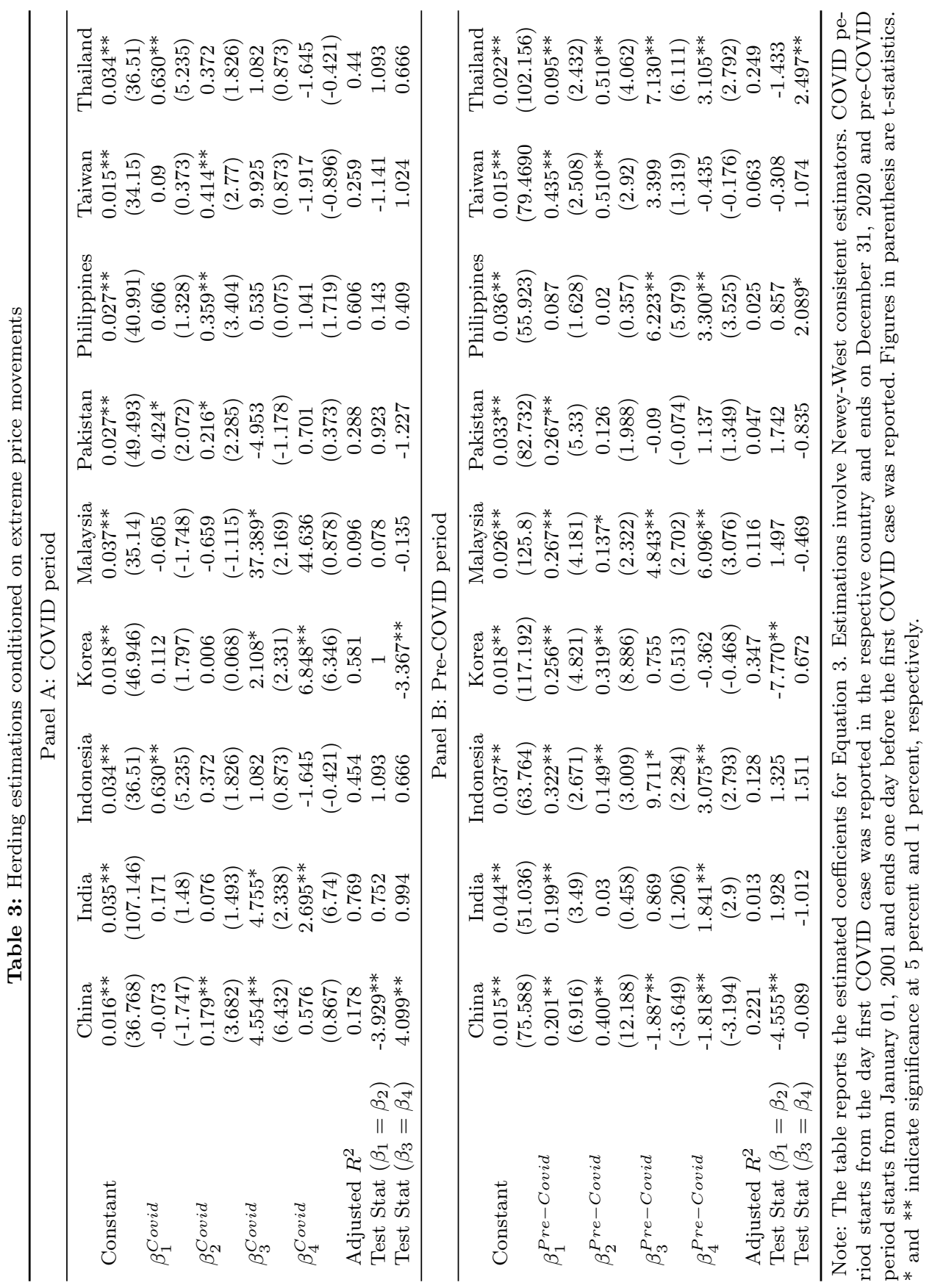


Investment behavior during the Covid Pandemic...

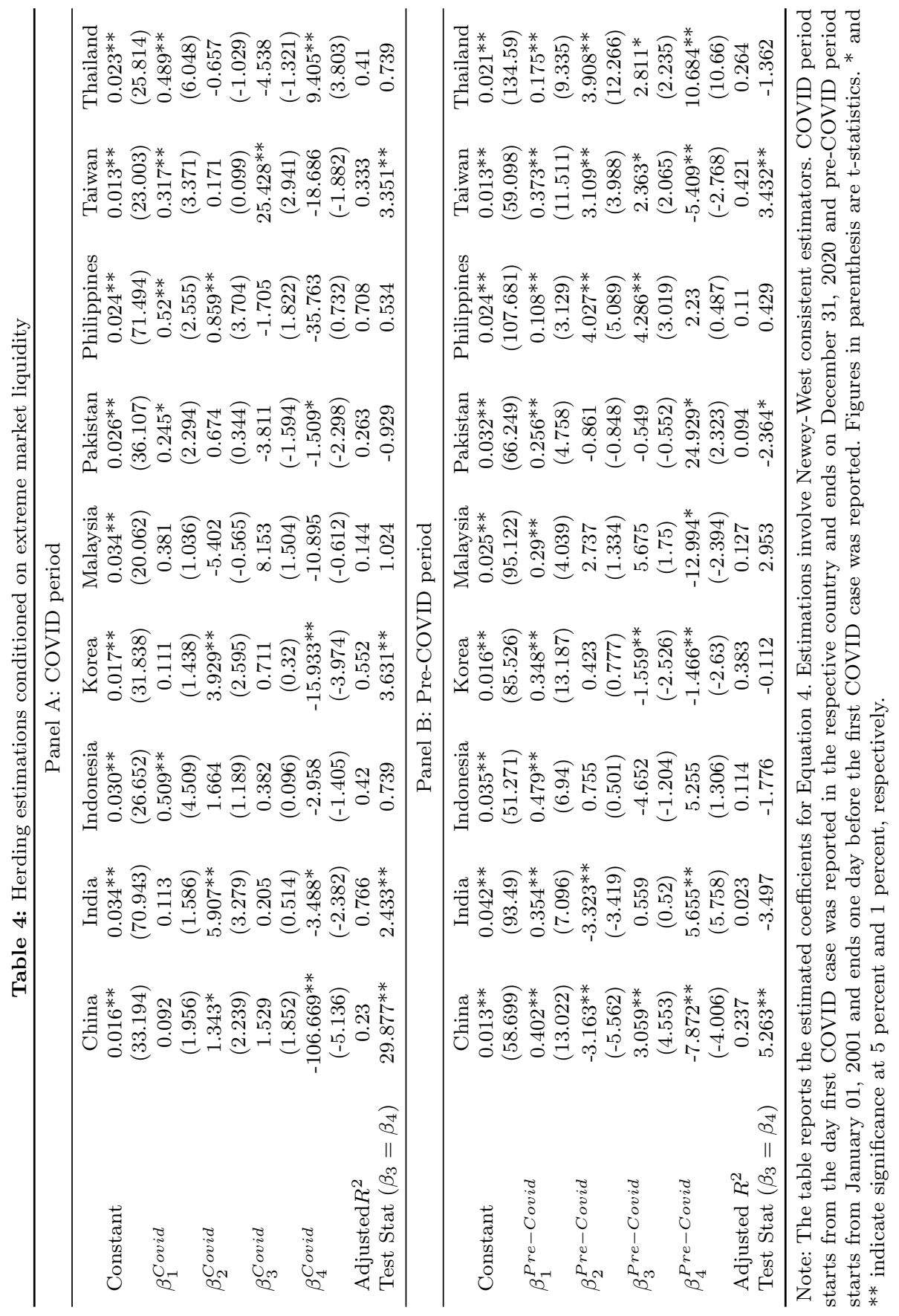

Business Review: (2021) 16(1):76-100 


\section{S. Tauseef}

Overall, our empirical tests indicate the presence of rational investor behavior in all markets over the COVID period. We observe herding on low trading volume days for few markets; however, herd formation was not observed for most markets when conditioned to domestic market factors (price movements and liquidity). Our findings on prevalence of efficient market conditions in Asian emerging markets contradict with the findings about significant herding reported in previous studies; for example, Chiang et al (2010) documented evidence of herd behavior in Asian markets. Nonetheless, our results based on the most recent data period hint about the improved information efficiency and transparency in Asian emerging markets.

\subsection{Role of US and Chinese Markets}

We now check the impact of return dynamics in foreign markets on local investor behavior over the COVID period. Panels A and B in Table 5 present the estimations of Equation 5 with respect to US and Chinese market returns, respectively. None of the coefficient for $\left(R_{U S}\right)^{2}$ and $\left(R_{C h}\right)^{2}$ is significantly negative suggesting that the local herds are not formed by the return dynamics of the dominant global and regional markets. Infact, we report significant positive coefficients of $R_{U S}$ for China, Malaysia, Pakistan, Philippines and Taiwan, indicating an increase in return dispersions in these markets with an absolute change in US return. With respect to regional influence, coefficient of $R_{C h}$ is significant only for Taiwan. Most importantly, the findings regarding local investment behavior in all markets after controlling for non-domestic factors remain the same and match the results from panel B of table 2. Our findings on insignificant impact of non-domestic factors is in line with low levels of integration of Asian emerging markets within global financial environment. 


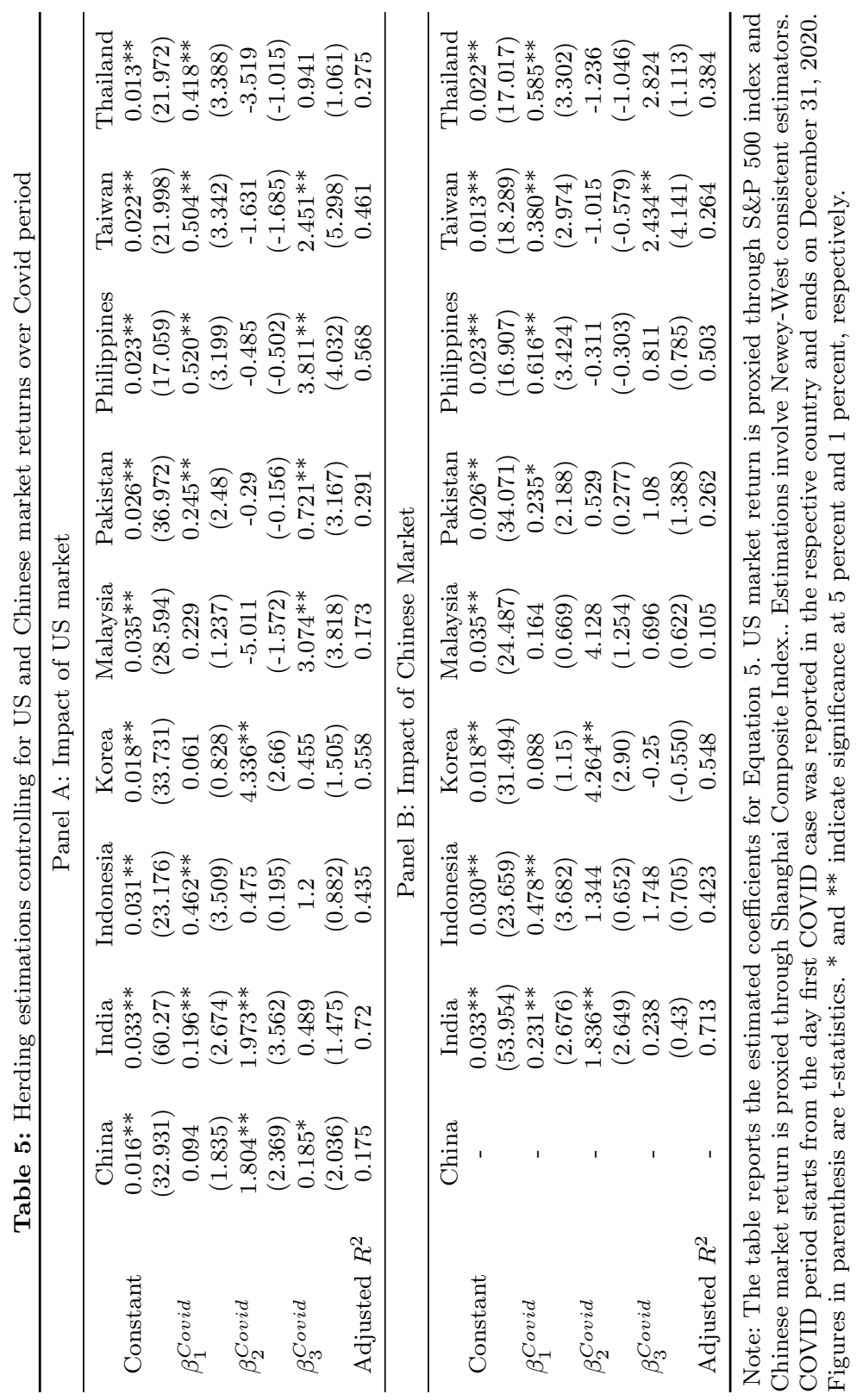

Business Review: (2021) 16(1):76-100 


\section{S. Tauseef}

\subsection{Robustness of results}

We perform a number of supplementary calculations to verify the robustness of our results. Though the dispersion measure we used is preferred due to its low sensitivity to the outliers, we employed cross section standard deviation (CSSD) as an alternate measure to confirm that our conclusions are not affected by the choice of dispersion measure. Secondly, we ran all models using quantile regression which does not require the conditions of linear regression. Also, we rechecked our results of conditional herding over pre-covid period using 5 percent and 1 percent criteria for defining extreme price movements and liquidity. We present the results in tables A2-A5 in the appendix. Our results remain qualitatively same with the use of alternate dispersion measure, regression model and defining criteria for extreme conditions.

We consider COVID period from the day first COVID case was reported in the respective country till December 31, 2020. To check for the possibility of irrational price behavior in the short-term period following COVID shock, we performed our estimations on a sub-period of initial 30 days during COVID outbreak and found similar results (presented in table A6 in appendix). Finally, our pre-COVID period comprises the period of financial crisis 2007-2008 which was characterized by low returns and high volatility in most equity markets. Since the investment behavior might be significantly different over the crisis period, we report the results of the crisis period separately in table A7 in the appendix. Over the financial crisis period, we observe some evidence of herding, conditional or unconditional, for China, India, Korea, Pakistan and Thailand. For four of these markets, investor herd behavior was not observed in overall pre-COVID period. In addition, we do not find any market that showed herding in overall pre-COVID period but not in financial crisis period. The comparisons suggest that our findings of investment behavior over the pre-COVID period is not impacted by the financial crisis period.

\section{Conclusion}

We investigate the investor behavior in the fast-growing Asian emerging markets before and after the COVID outbreak using the data for the period 2001 to 2020. Our findings indicate that rational price behavior prevailed in all markets over the COVID period and herding manifested itself only in few countries during the low trading volume days. Interestingly enough, our comparison of the pre-COVID and COVID periods shows a significant shift in price behavior away from herding and in favor of market efficiency for the emerging markets of China, India and Korea. Given the evidence of herding during crisis in literature, our findings of rational investor behavior over the COVID period are unique. We attribute the findings supporting rationality hypothesis in Asian emerging markets to the improved information quality, various financial liberalization measures, and a substantial rise in available equity base in these markets. Our findings will be of particular interest to the investors, particularly those with a global outlook. Evidence in support of rational price behavior suggests that 
occurrence of destabilizing outcomes is less likely and, hence, could provide confidence to the global portfolio investors to increase their portfolio allocations in these markets.

\section{References}

Agarwal S, Chiu IM, Liu C, Rhee SG (2011) The brokerage firm effect in herding: Evidence from indonesia. Journal of Financial Research 34(3):461-479

Akbar US, Oad Rajput SK, Bhutto NA (2019) Do investors herd with industries or markets? evidence from pakistan stock exchange. Cogent Economics \& Finance 7(1):1698,089

Brahmana R, Hooy CW, Ahmad Z (2012) The role of herd behaviour in determining the investor's monday irrationality. Asian Academy of Management Journal of Accounting \& Finance 8(2)

Chang CY, Chen HL, Jiang ZR (2012) Portfolio performance in relation to herding behavior in the taiwan stock market. Emerging Markets Finance and Trade 48(sup2):82-104

Chang EC, Cheng JW, Khorana A (2000) An examination of herd behavior in equity markets: An international perspective. Journal of Banking \& Finance 24(10):1651-1679

Chauhan Y, Ahmad N, Aggarwal V, Chandra A (2020) Herd behaviour and asset pricing in the indian stock market. IIMB Management Review 32(2):143-152

Chiang TC, Li J, Tan L (2010) Empirical investigation of herding behavior in chinese stock markets: Evidence from quantile regression analysis. Global Finance Journal 21(1):111124

Chong TTL, Liu X, Zhu C (2017) What explains herd behavior in the chinese stock market? Journal of Behavioral Finance 18(4):448-456

Christie WG, Huang RD (1995) Following the pied piper: Do individual returns herd around the market? Financial Analysts Journal 51(4):31-37

Conover CM, Jensen GR, Johnson RR (2002) Emerging markets: when are they worth it? Financial Analysts Journal 58(2):86-95

Dehghani P, Sapian RZZ (2014) Sectoral herding behavior in the aftermarket of malaysian ipos. Venture Capital 16(3):227-246

Demirer R, Kutan AM (2006) Does herding behavior exist in chinese stock markets? Journal of international Financial markets, institutions and money 16(2):123-142

Gelos RG, Wei SJ (2005) Transparency and international portfolio holdings. The Journal of Finance 60(6):2987-3020

Gompers PA, Metrick A (2001) Institutional investors and equity prices. The quarterly journal of Economics 116(1):229-259

Goodfellow C, Bohl MT, Gebka B (2009) Together we invest? individual and institutional investors' trading behaviour in poland. International Review of Financial Analysis 18(4):212-221

Hirshleifer D, Subrahmanyam A, Titman S (1994) Security analysis and trading patterns when some investors receive information before others. The Journal of finance 49(5):1665-1698

Huang TC, Wang KY (2017) Investors fear and herding behavior: evidence from the taiwan stock market. Emerging Markets Finance and Trade 53(10):2259-2278

Indārs ER, Savin A, Lublóy Á (2019) Herding behaviour in an emerging market: Evidence from the moscow exchange. Emerging Markets Review 38:468-487

Jabeen S, Rizavi SS (2019) Herd behaviour, short-lived phenomenon: Evidence from pakistan stock exchange. The Lahore Journal of Business 8(2)

Javaira Z, Hassan A (2015) An examination of herding behavior in pakistani stock market. International journal of emerging markets

Mobarek A, Mollah S, Keasey K (2014) A cross-country analysis of herd behavior in europe. Journal of International Financial Markets, Institutions and Money 32:107-127

Newey WK, West KD (2017) A simple, positive semi-definite, heteroskedasticity and autocorrelation consistent covariance matrix. No1 (33) 2014 p 125

OECD (2019) Equity market review of asia 2019. OECD Capital Market Series, Paris

Prosad JM, Kapoor S, Sengupta J (2012) An examination of herd behavior: An empirical evidence from indian equity market. International Journal of Trade, Economics and Finance $3(2): 154$

Business Review: (2021) 16(1):76-100 


\section{S. Tauseef}

Tan L, Chiang TC, Mason JR, Nelling E (2008) Herding behavior in chinese stock markets: An examination of a and $b$ shares. Pacific-Basin finance journal 16(1-2):61-77

Yousaf I, Ali S, Shah SZA (2018) Herding behavior in ramadan and financial crises: the case of the pakistani stock market. Financial Innovation 4(1):1-14

Zhou RT, Lai RN (2009) Herding and information based trading. Journal of Empirical Finance 16(3):388-393

\section{Appendix}

Table A1: Sample countries

\begin{tabular}{llll}
\hline Country & Equity Index & $\begin{array}{l}\text { Date of first } \\
\text { COVID case }\end{array}$ & $\begin{array}{l}\text { Total } \\
\text { cases (31-12-20) }\end{array}$ \\
\hline China & Shanghai Composite & 17-Nov-19 & 87052 \\
India & Nifty 50 & 30-Jan-20 & 10286329 \\
Indonesia & IDX Composite & 2-Mar-20 & 743198 \\
Korea & KOSPI & 20-Jan-20 & 60740 \\
Malaysia & KLCI & 25-Jan-20 & 113010 \\
Pakistan & KSE 100 & 26-Feb-20 & 479715 \\
Philippines & PSEI Composite & 30-Jan-20 & 474055 \\
Taiwan & TAIEX & 21-Jan-20 & 799 \\
Thailand & SET & 13-Jan-20 & 6884 \\
\hline
\end{tabular}

Note: The table reports the major equity market index, date of first COVID case and number of total COVID cases for nine Asian emerging countries. 
Investment behavior during the Covid Pandemic...

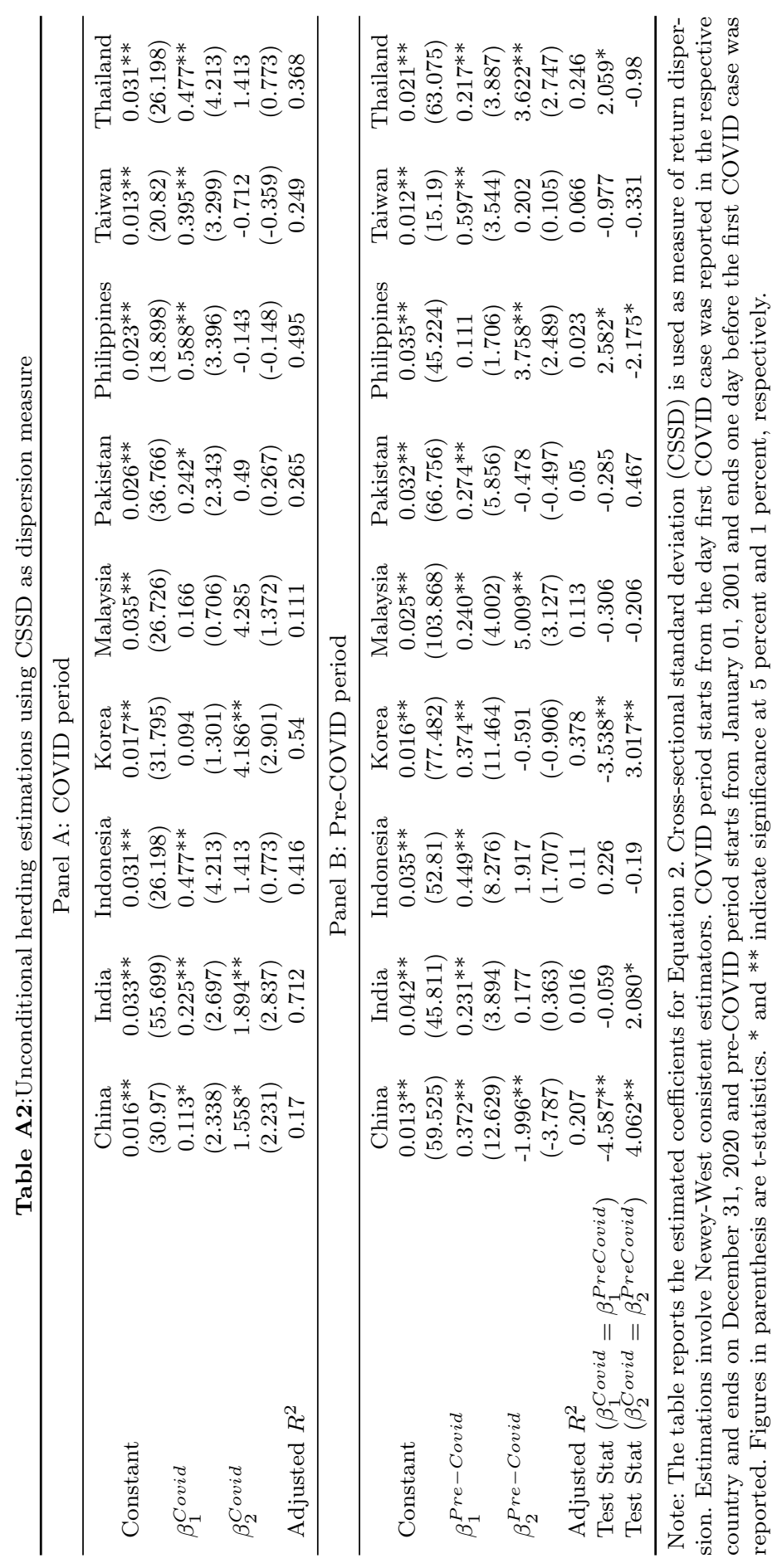

Business Review: (2021) 16(1):76-100 


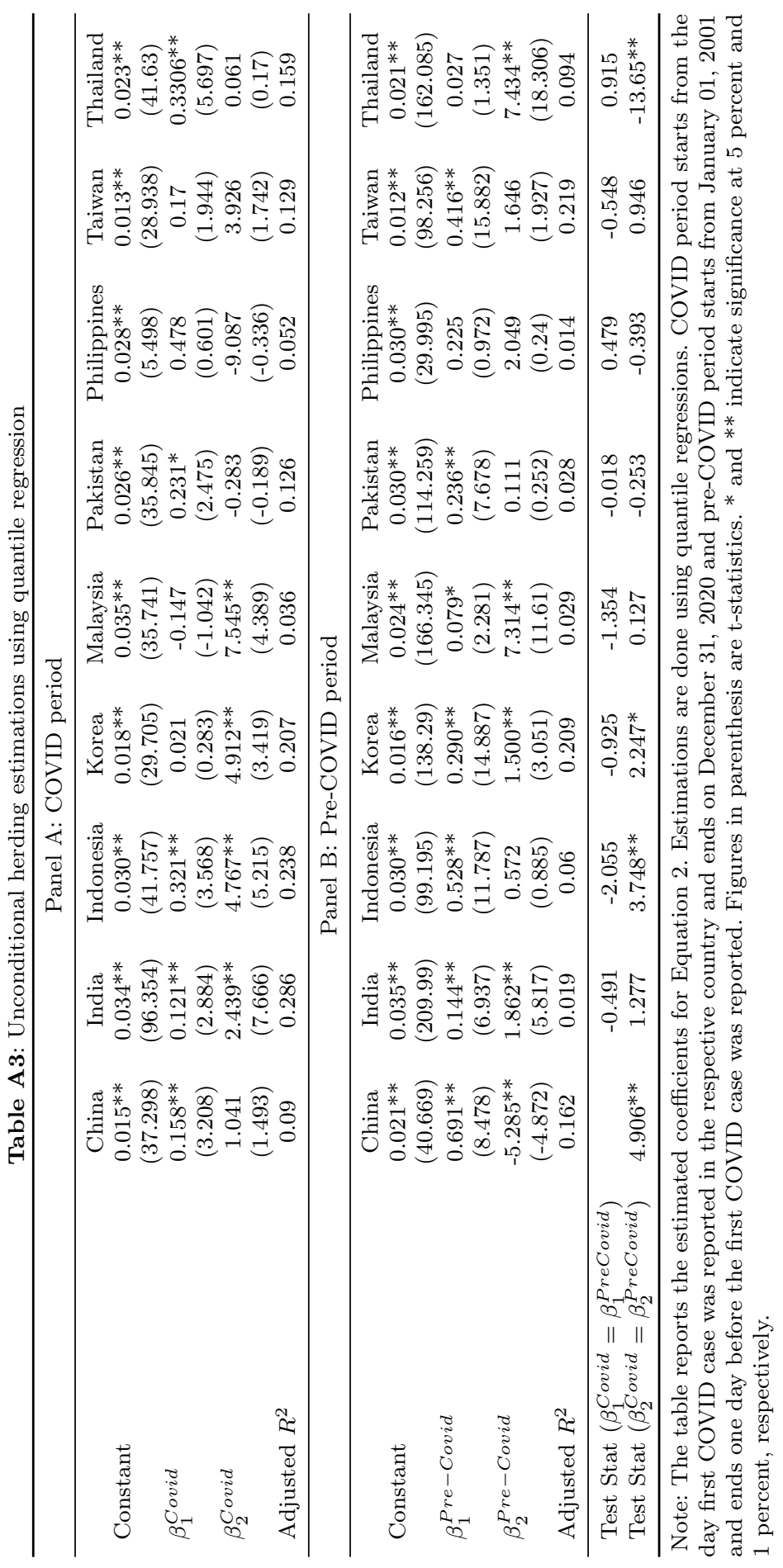


Investment behavior during the Covid Pandemic...

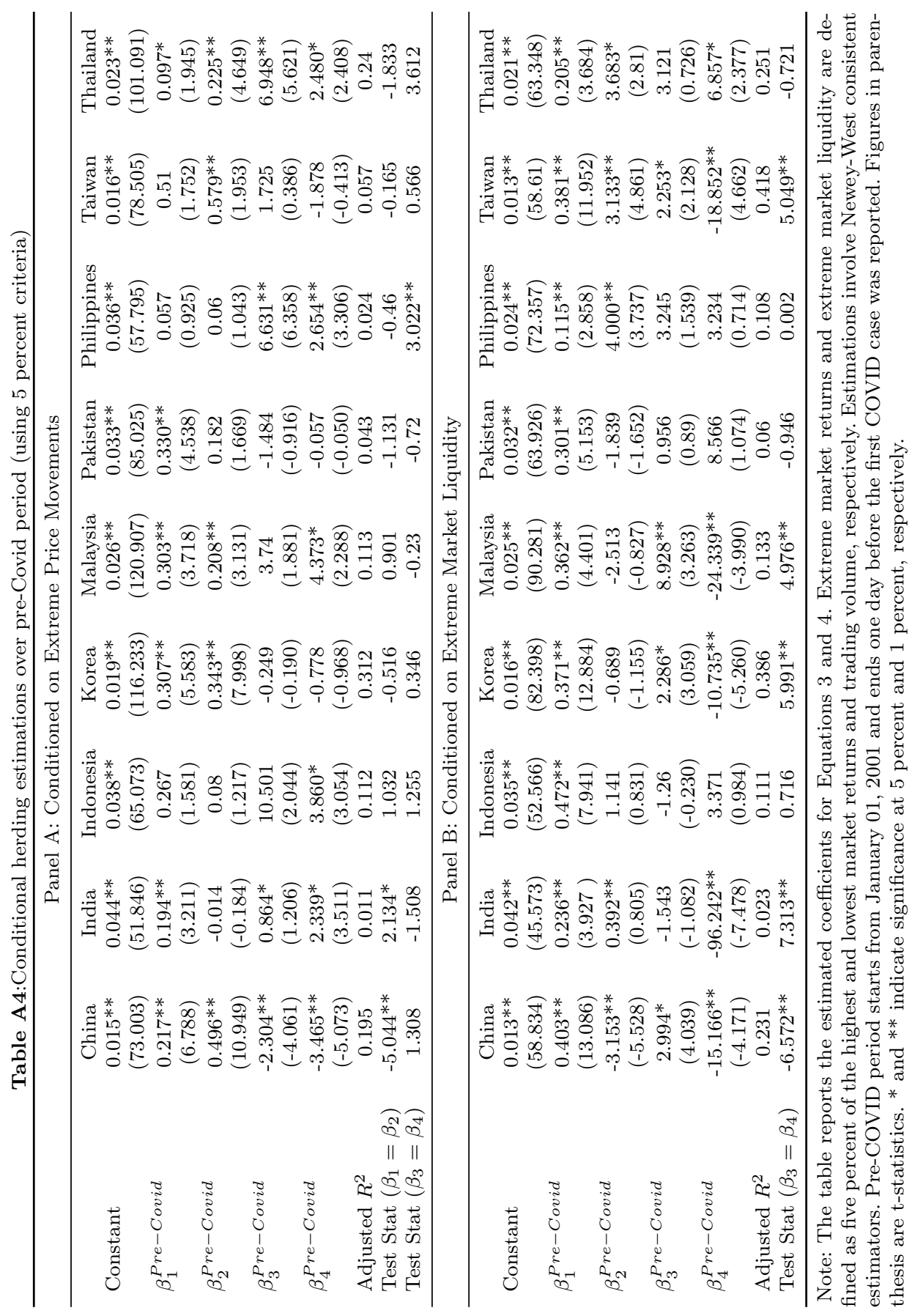

Business Review: (2021) 16(1):76-100 


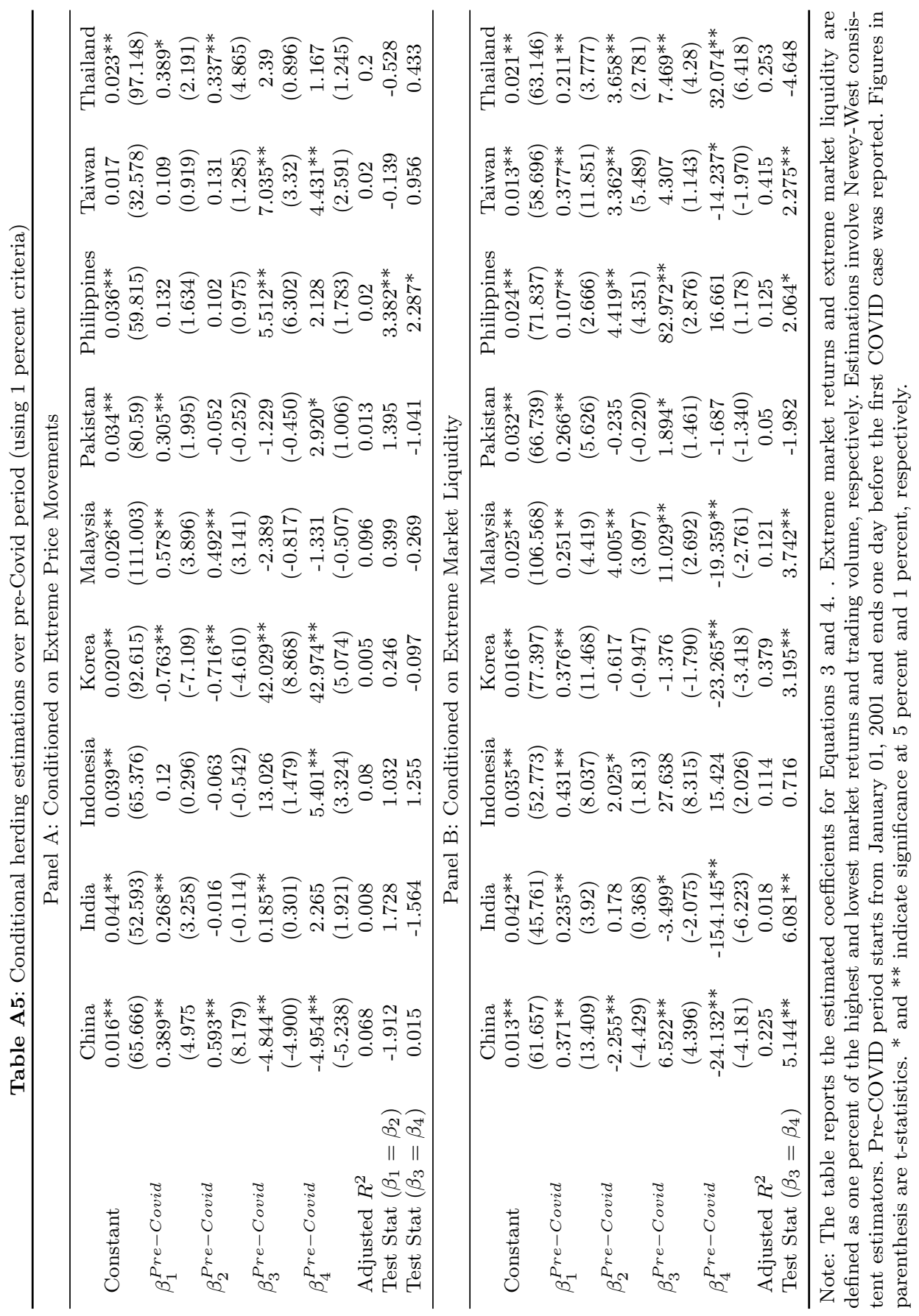




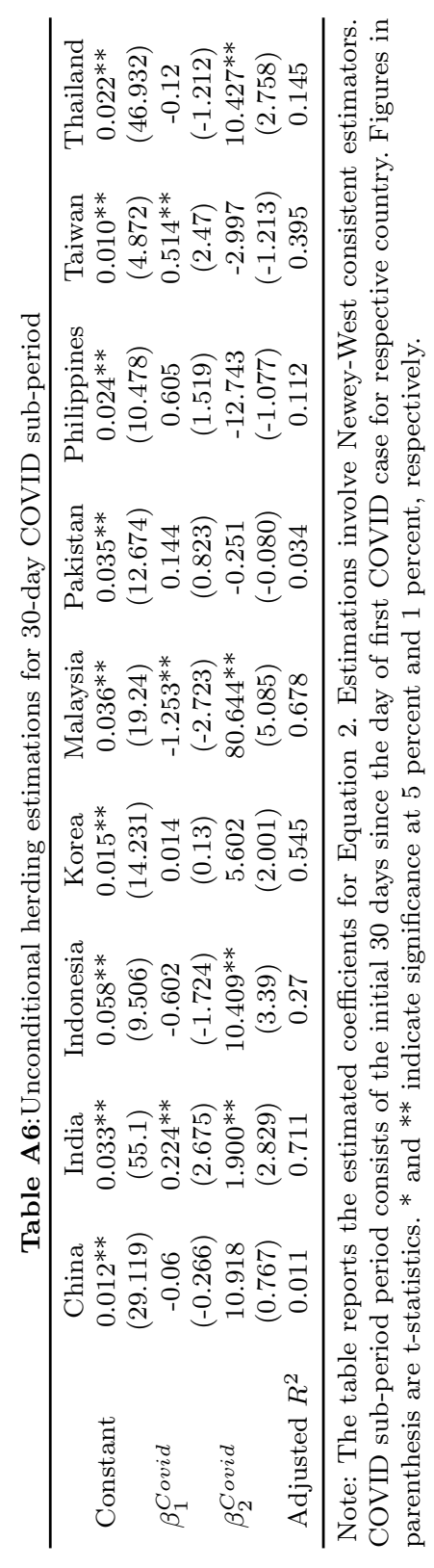

Business Review: (2021) 16(1):76-100 


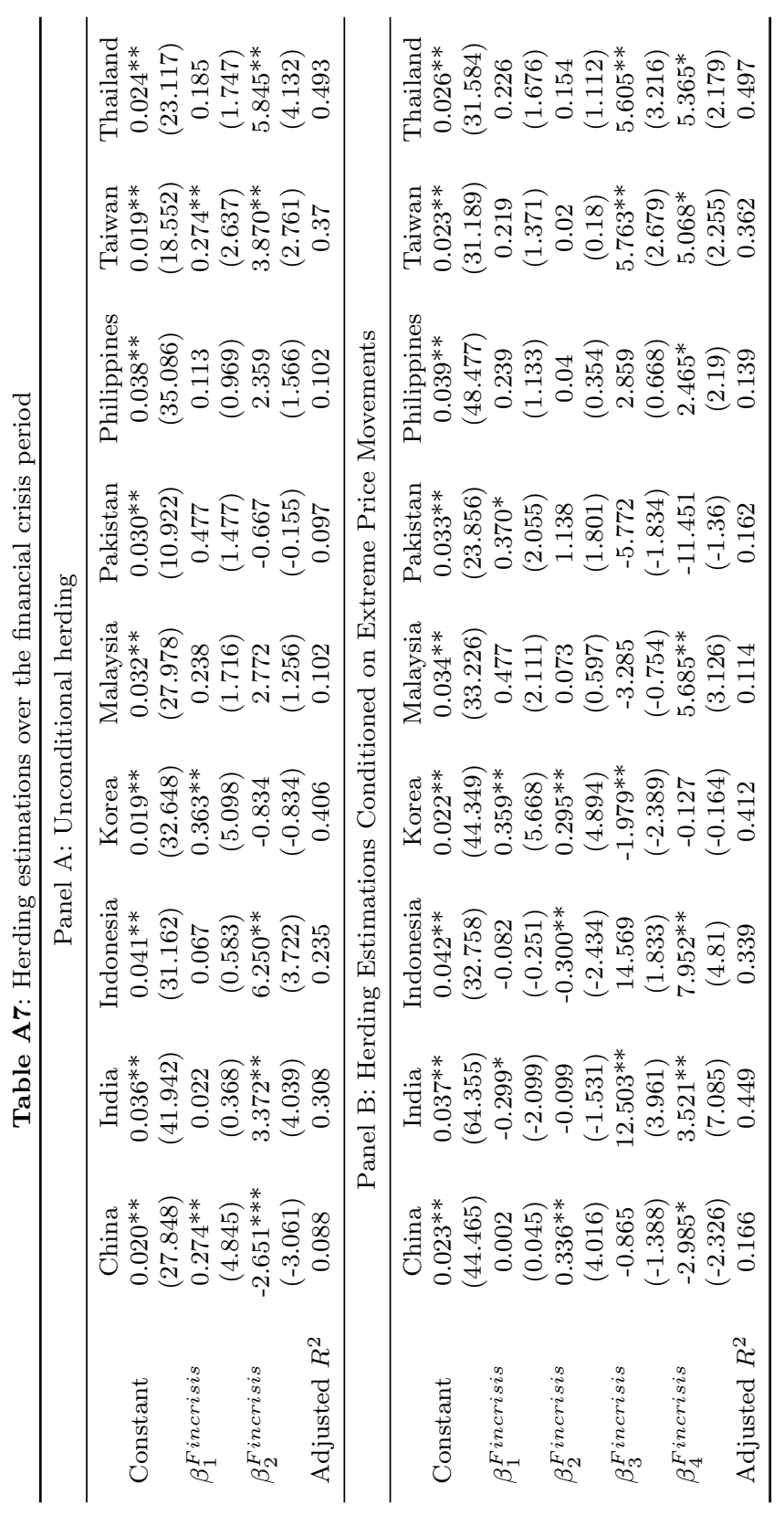




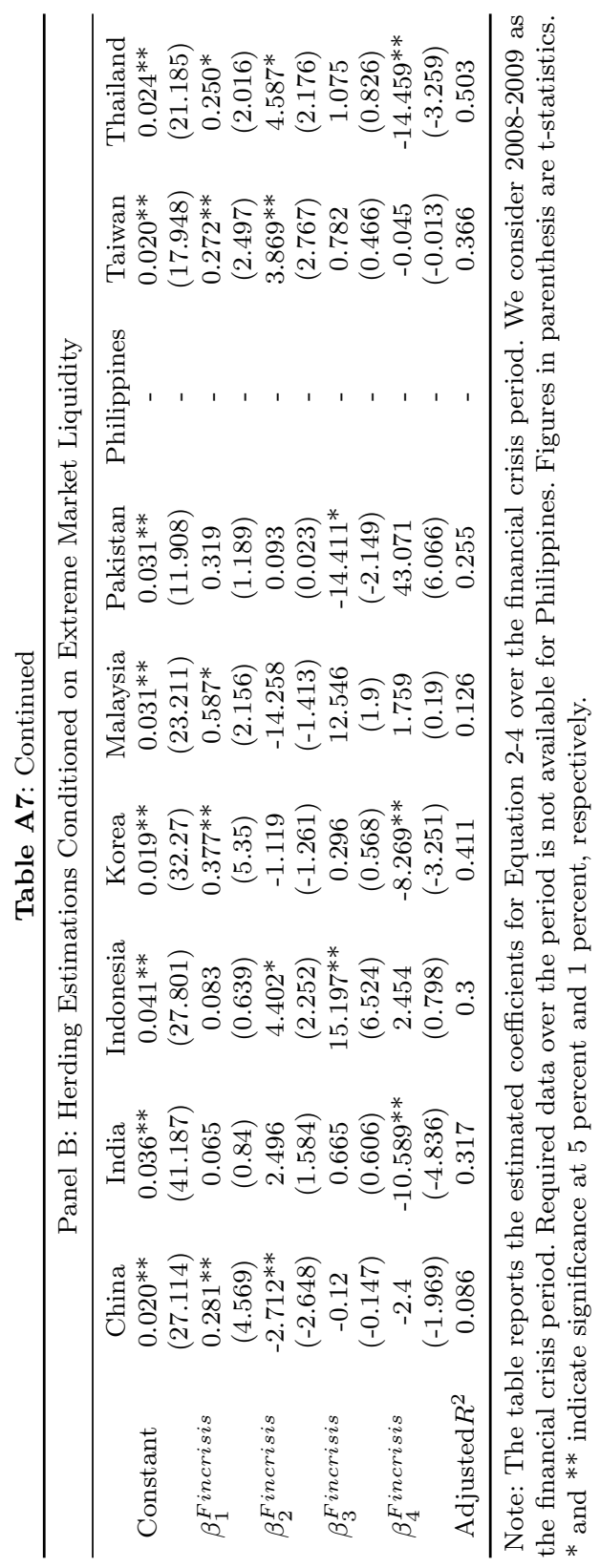

